ARENBERG, D. Concept identification and age Prnceedings of the 8th Intemational Congress of Gerontology. Vol. 2, Washington, 1969. P. 59. (A bstract)

ARENBERG, D. Equivalence of information in concept identification. Psychological Bulletin. in press.
NOTES

1. Reprint requests should be sent to Phillip $R$. Thome, Gerontology Research Center, Baltimore City Hospitals, Baltimore, Maryland 2124.

2. De Morgan's theorem can be expressed as $\bar{A}+\bar{B}=\overline{A B}$. Hence, a NAND gate will yield an $A N D$ function if followed by an inverter or an OR function if preceded by inverters. This is accomplished by reversing the polarity of power applied to the selection switches

3 . These circuits were constructed on 12 (2 to a card) single-sided $3 \frac{1}{4} \times 4 \frac{1}{4}$ in. printed circuit cards. A negative is available from the authors. (See Fig. 3.)

4. Art and photographic contributions of Rowland Schnick are gratefully acknowledged.

\title{
A simple and inexpensive method to measure urinary excretion in nonhuman primates
}

\section{E. THOMSEN and L. H. MENDOW, TULANE UNIVERSITY DELTA REGIONAL PRIMATE RESEARCH CENTER, Covington, Louisiana 70433}

A simple and inexpensive automated method is described for simultaneous recording of time of day and frequency of urinary excretion. $A$ 24-h event recond for eight thesus monkeys illustrates possible usefulness of the method in detcrmining individual differences, response to environmental factors, and diumal patterns.

While time, frequency, and amount of urinary excretion have been used in studies of water balance, circadian rhythms, and conditioning, few researchers have devised automated ways of obtaining the data. Most frequently, the amount of urine is recorded either in 24-h samples or within smaller periods of time (Dykman et al, 1962; Hoshizaki et al, 1969; Rohles \& Osbaldiston, 1969). Recently, Nicholson and Warwick (1969) used circuits employing either temperature- or light-sensitive transistors to measure the time at which urination occurred. They could record the "amount" of urine if a drop tube and counter were also used. Another method to automatically record

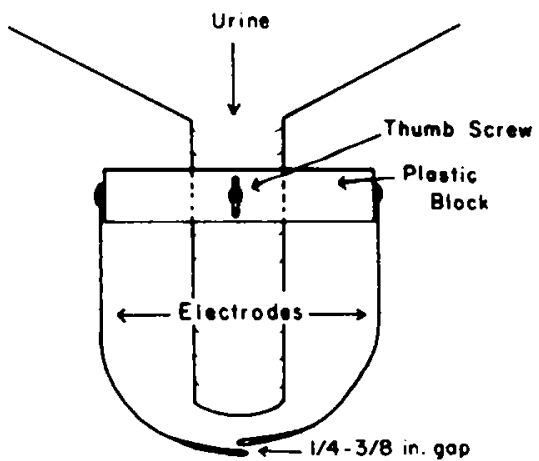

Fig. 1. Electrode placement on urine drain spout. amount and time of urine flow used an aneroid manometer in a water-filled system (Feldmahn et al, 1960). This method is expensive and space consuming.

The apparatus to be reported here records the time of day and frequency of urination and can be adapted to record "volume" by adding a drop tube and counter similar to that used by Nicholson and Warwick. The basic apparatus consists of two electrodes affixed to the drain spout of the urine collection pan and a current-sensitive relay circuit. The output of the relay can be connected to any event recorder. Eight of these units are currently being used simultaneously to measure the urination patterns of eight rhesus monkeys. The unit cost for electrodes and relay circuit is under $\$ 6$.

The electrode assembly and method of mount is shown in Fig. 1. The electrodes are constructed from 30-ga stainless steel sheets cut into $1 / 2 \times 3$ in. pieces. These are attached to a Plexiglas block of sufficient width to prevent a short between the spout and electrodes and are of sufficient length so that they can extend below the spout before being bent inward. One electrode is bent so that it is slightly higher and extends inward over the other so that the vertical fall of the urine will not miss the electrodes. A gap of approximately $1 / 4$ to $3 / 8$ in. is set between the tips of the electrodes so that occasional drops of urine that may lodge and be delayed on a feces separation screen do not record as urination. The electrodes are cleaned every 2 to 3 weeks to prevent an increase in electrode resistance from corrosion. They are inspected twice daily on the cages to remove animal hair that may collect on the electrodes and cause a temporary short.

The current-sensitive relay circuit (Fig. 2) is a modification of those commonly used to measure contact (see, e.g., Jarvik \& Carley, 1964). The transistor, $2 \mathrm{~N} 1415$, is used to drive the Type 11F-550 Ohm Sigma relay. In addition, a 100K resistor is added to provide transistor turn-off current and a 1 -meg potentiometer is used to vary the bias turn on current. The potentiometer is adjusted by setting it at maximum resistance, applying a direct short across the electrodes, and then decreasing the resistance until the relay pulls in. The potentiometer is then adjusted slightly, with the short removed, to make consistent relay closures when urine is poured into the pan.

A 24-h record for eight rhesus monkeys (Fig. 3) illustrates the patterns and frequency of urination as recorded on an Esterline Angus event recorder. Each group of eight lines reads from right to left for ime of day and includes a 4h period. The lower line in each set represents Animal 1 and the top line is Animal 8. The top eight lines begin at midnight $(M)$ and end at 4 a.m. The next set begins at $4 \mathrm{a} . \mathrm{m}$. and ends at 8 a.m. This is the pattern for each set Dne pattern of malfunction that occurs is seen from noon (N) until 4 p.m. for Animal 3. It appears that urination lasts for several minutes during each of several times followed by repeated voidings every few minutes. This pattern occurs when one or two hairs effectively decrease the electrode distance so that the last drops of urine after urination travel down the hairs and make a sufficient short for the contact sensor to operate.

While the first author is interested in a detailed analysis of urinary excretion over long periods of time and in comparing

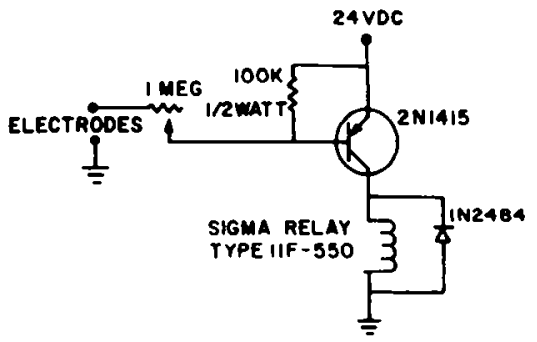

Fig. 2. Schematic diagram of current-sensitive relay circuit. 

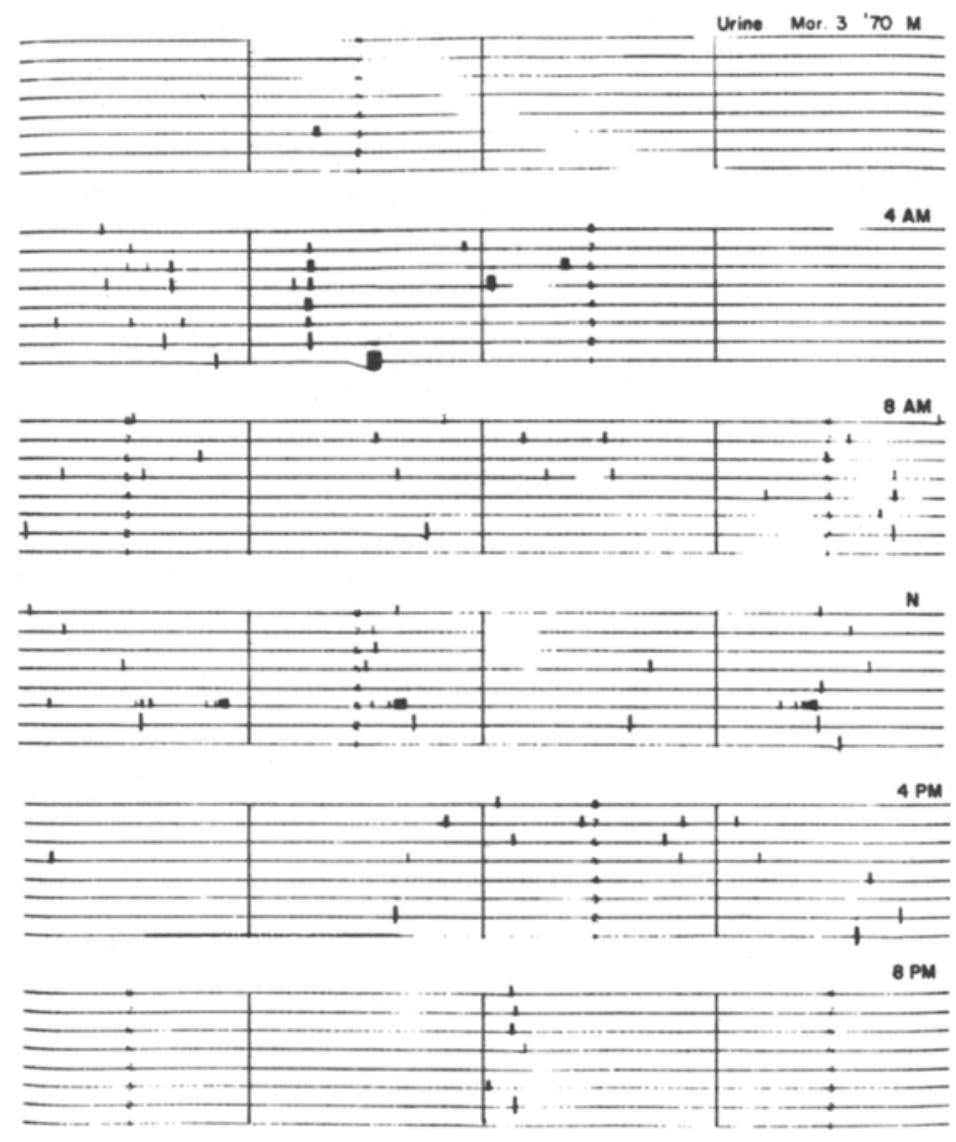

these patterns to time and amount of water intake, activity, and other measures, several interesting findings can be obtained from the single-day record in Fig. 3. Six of eight animals urinated within a few minutes of each other at 6:45 a.m. and again at approximately 9:50 p.m. While the time of urination is more variable at other times of the day, seven animals urinated within a $15-\mathrm{min}$ period at approximately $12: 30$ p.m. and six animals urinated within to the test room.
Fig. 3. A 24-h event record showing time of day of urination for eight rhesus monkeys. The record starts with midnight (M) in the upper right hand corner and reads from right to left in 4-h blocks.

interest. The frequency of urination is 4 , $12,12,6,20,11,15$, and 9 for Animals 1 through 8, respectively. Animal 1 urinated a large amount at 6:30 a.m., and then voided only three times thereafter. Animal 3 voided at $2: 45$ a.m., whereas no other animals voided in the middle of the night.

\section{REFERENCES}

DYKMAN, R. A.. CORSON, S. A., REESF. W. G., \& SEAGER, L. D. Inhibition of urine flow as a component of the conditional defense reaction. Psychosomatic Medicine, 1962. 24, 177.186.

IEELDMAHN, A. L, SMITH, W. K., \& LEVENTHAL, C. M. Diurnal patterns of micturation and drinking in rhesus monkeys. Annals of the New York Academy of Science, $1960,85,828-841$.

HOSHIZAKI, T., ADEY, W. R., MEEHAN, J. P. WALTER, D. O., BERKHAUT, J. I., and CAMPEAU, E. Central nervous, cardiovascular, and metabolic data of a Macaca nemestrina during a 30-day experiment. In F. H. Rohles (Ed.), Circadion thythms in nonhuman primates, Basel: S. Karger, 1969. Pp. 8-38.

JARVIK, M. E., \& CARLEY, J. L. A simple circuit for contact responses. Journal of the Experimental Analysis of Behavior, 1964, 7, 82.

NICHOLSON, J. D., \& WARWICK, I. S. A temperature and light sensitive electronic circuit. Joumal of Science Technology, 1969, $15,86-88$.

ROHLES, F, H., JR., \& OSBALDISTON, G. Social entrainment of biorhythms in thesus monkeys. In F. H. Rohles (Ed.), Circadian rythms in nonhuman primates. Basel: S. Karger, 1969. Pp. 39-51.

\section{NOTE}

1. This paper was supported by NIH Grant

Individual differences are also of

FR-00164 and HD 03915 .

\section{An electroluminescent lamp device for critical flicker fusion and apparent motion}

C. C. BROWN and D. KRAUSMAN, MARYLAND PSYCHIATRIC RESEARCH CENTER, Box 3235, Catonsville, Maryland 21228

$A$ circuit that uses electroluminescent lamps as light sources for the study of critical flicker fusion (CFF) and apparent motion phenomena is described. The technique involves the modulation of a $2 \cdot \mathrm{KHz}$ exciting current with a multivibrator-formed pulse adjustable over a suitable range of frequencies. Components are readily available from commercial sources.

Wide use of the perceptual test of critical flicker fusion (CFF) and apparent motion phenomena is limited by the expense and complexity of commercial circuitry. Most of this equipment uses xenon-filled crater lamps (RC 1130 B) which require high-power vacuum-tube driver circuits. A further disadvantage is that this type of light source produces an intense spot rather than a uniform field of illumination. 